\title{
DE LA GITANILLA A LA SABIA FLORA MALSABIDILLA. EL GÉNERO, EL PERSONAJE Y EL MATRIMONIO ${ }^{1}$
}

\author{
María SoledAd ARREDONDo \\ Universidad Complutense de Madrid \\ msarredo@filol.ucm.es
}

Era algo desenvuelta, pero no de modo que descubriese algún género de deshonestidad; antes, con ser aguda, era tan honesta... $\quad$ (La gitanilla)

Sabe, pues, que mis padres fueron gitanos... Llamábame en Cantillana el sol de Egipto, título que se dio a los méritos de mi belleza, más ilustrados con los donaires de mis labios...

(La sabia Flora malsabidilla)

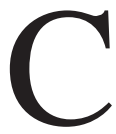

uando Cervantes publica en 1613 las Novelas Ejemplares no solo creó la novela corta española (González de Amezúa 1956), sino que propició una serie de novedades que los autores contemporáneos trasladaron a otros géneros literarios. A partir de la colección cervantina se introdujeron personajes, ambientes y temas españoles que enriquecieron los anteriores modelos italianos, y que fueron admirados y seguidos muy especialmente en Francia. Las novelas cervantinas fueron leídas y traducidas allí, pero también adaptadas (Cioranescu 1983) a otros géneros, especialmente al dramático. Su éxito se extendió a títulos y escritores cercanos, y es notable la huella de otros autores españoles en Francia, como Salas Barbadillo o Pérez de Montalbán, cuyas obras merecieron adaptaciones francesas, en una amplia secuela de parentescos bien estudiada (Hautcoeur Pérez-Espejo 2005).

Ya he señalado en otra ocasión (Arredondo 1988) que uno de los primeros en destacar la influencia de la narrativa breve cervantina fue el francés Charles Sorel, autor de dos colecciones de novelas cortas (Nouvelles françaises, 1623, y Nouvelles choisies, 1645), que se declaró conocedor y admirador de las Ejemplares

1 Este trabajo se inscribe en el Proyecto de Investigación De la biblioteca particular al canon literario en los Siglos de Oro (хVI у хVII), ref. FFI 2012-35894. 
al menos en dos ocasiones: primero en Le Berger Extravagant (1627), una anti-novela que parodiaba los libros pastoriles y, en general, la narrativa idealizada (Arredondo 1987), y al final de su carrera en La Bibliothèque Française (1667), una obra de erudición y crítica, que recogía los mejores títulos de diversos géneros escritos en francés, tanto originales como traducciones. En Le Berger Extravagant $^{2}$ comparaba la narrativa española con la francesa, y afirmaba lo siguiente sobre la verosimilitud:

N'est-il pas vrai que si un auteur François nous donnait un livre ou l'ón vit les façons de faire de ces egiptiennes ou de ces irlandaises qui demandent l'aumone par Paris et qu'il y mist aussi de sottes chansons comme il y en a dans La belle egyptienne de Cervantes nous trouverions cela plustot niais que d'advouer que cela fut excellent...? (Remarques sur le XIII livre: 500).

Este reproche de Sorel, que era partidario de la literatura realista, es una de las primeras menciones de La gitanilla, traducida al francés desde 1615 y adaptada al teatro en 1628 por Alexandre Hardy (Ruiz Álvarez 1991). Me interesa resaltar la mención de las mujeres extranjeras que mendigaban por París, «égiptiennes»e «irlandaises», así como la presencia de cancioncillas, "sottes chansons», con las que se ganaban la vida: tonterías o simplezas, pero, además, mezcolanza o inserción innecesaria en los relatos de piezas en verso; las dos observaciones afectan, respectivamente, al personaje femenino y a la mixtura genérica.

La segunda mención de las novelas cervantinas se halla en la Bibliothèque Française 3 cuando Sorel se refiere a los libros útiles, «profitables», entre los que hallamos las novelas cortas, de las que hace una pequeña historia comparativa ${ }^{4}, \mathrm{y}$ en donde aparece de nuevo el concepto de verosimilitud:

On commençoit aussi de connoistre ce qu'estoit des choses vray-semblables, par de petites narrations dont la mode vint, qui s'appelloient des nouvelles [...] Nous avions desja veu les Nouvelles de Boccace et celles de la Reyne de Navarre [...] Nous avions veu encore les Histoires Tragiques de Bandel, qu'on avoit traduites de l'italien, qui estoient autant de nouvelles, mais les espagnols nous en donnerent de plus naturelles et de plus circonstantiées, qui furent les Nouvelles de Miguel de Cervantes... (Bibliothèque Française: 324-325).

A continuación Sorel se refiere a las novelas de Pérez de Montalbán y «otros», sin precisar títulos: «on a vu depuis celles de Montalban et d'autres...»; pero destacando que su lectura era recomendable para las damas: «au lieu que quelques

Citamos por la ed. de París: Toussainct du Bray, 1627.

Citamos por la ed. de Myron Low Kocher (1966).

4 Me refiero a esta cuestión en Arredondo, «Frontières et bibliothèques pour les Novelas du Siècle d'Or: Italie, France, Espagne», en prensa. 
unes d'auparavant estoient fort condamnées, comme celles de Boccace qui sont de très mauvais exemple». En este caso el mérito de las novelitas españolas radica en su moralidad o castidad, comparadas con las italianas.

Conviene detenerse en las apreciaciones sucesivas del escritor francés, porque inciden en aspectos genéricos, de personaje y de moralidad de los textos, sobre los que reflexionaron, sin duda, los autores españoles coetáneos y, entre ellos, Salas Barbadillo cuando publica La sabia Flora malsabidilla en 1621. Precisamente la proximidad en fechas, 1613 y 1621; la amistad de Salas y Cervantes ${ }^{5}$, con el que coincidía en la congregación de Esclavos del Oratorio del Olivar; y el conocimiento de una colección narrativa que el mismo Salas había aprobado sugieren la posibilidad de que La gitanilla como novela y Preciosa como personaje fueran los detonantes para que, lejos de similitudes, Salas Barbadillo concibiera un personaje absolutamente opuesto y lo insertara en otro género literario, una comedia en prosa, llevando a cabo una de sus muchas «exploraciones» (García Santo Tomás 2013: 46) dramáticas y narrativas.

Como ya sabemos (Bourland 1927), no hay que cruzar los Pirineos para percibir la influencia y secuelas de las novelas cortas cervantinas. Sin embargo, el número de ejemplares de las mismas hallados en bibliotecas particulares de la época es escaso: en una investigación (Arredondo 2012) sobre la prosa de ficción que aparece en inventarios entre los años 1651-1700 sólo hemos hallado cuatro ejemplares de las Novelas... de Cervantes, frente a veinticuatro de Don Quijote de la Mancha. Es curioso que, pese al éxito de la colección cervantina y su influencia posterior, la investigación sobre ochenta y tres inventarios de bibliotecas particulares arroje cifras tan pobres, aunque haya poca novela, en general, en comparación con poesía, teatro y libros de devoción y de uso profesional. No obstante, el subgénero de la prosa de ficción mejor representado por su cuantía es, precisamente, la novela corta, desde Boccaccio y Giraldi Cinthio, a Cervantes, Agreda y Vargas, Zayas, etc.; pero las obras de Salas Barbadillo, por ejemplo, son escasas: sólo Corrección de vicios, Estafeta del dios Momo y Fiestas de la boda de la incasable mal casada; y tampoco aparece nuestra Sabia Flora... entre los ejemplares de teatro reseñados en dichos inventarios. Parece, pues, que las valoraciones críticas actuales no siempre coinciden con datos de la época, aparentemente objetivos.

Por otra parte, en un artículo de 1976 Juan Goytisolo ${ }^{6}$ lamentaba la pacatería de la crítica respecto al estudio del erotismo en la literatura, y la poca atención dedicada hasta entonces a personajes marginales, como la protagonista de $\mathrm{La} \mathrm{Lo}$ zana andaluza, que se me antoja tan insólita $-\mathrm{y}$ poco virtuosa- como nuestra gitana Flora. De la misma manera Evangelina Rodríguez Cuadros (1979) se quejaba, por las mismas fechas, de la marginación de la novela corta áurea.

\footnotetext{
5 Ver a este respecto Manoukian (2011), con bibliografía actualizada a la que remito.

6 Fue posteriormente recogido en Disidencias (1996).
} 
Transcurridos más de treinta años de ambas autorizadas opiniones, ni la novela corta es ya un género marginado, ni la escasa moralidad de los personajes femeninos novelescos ha sido óbice para estudios minuciosos. Por ello, en este monográfico sobre novela corta he querido apuntar algunas cuestiones periféricas (como la relación novela-comedia-miscelánea), y modificaciones tangenciales de nuestro género, como el distinto tratamiento del personaje femenino y del tema del matrimonio, tan presente en la ficción áurea. Aunque La sabia Flora malsabidilla no es una novela corta, es posible que surgiera de La gitanilla cervantina, y representa bien una cuestión teórica capital en la prosa áurea: la mixtura genérica (Arredondo, 2006) «barroca» (sobrecargada de elementos varios), adjetivo acertadamente empleado por Ripoll (1991) en su imprescindible Catálogo... En las líneas que siguen me propongo señalar tres de las novedades de La sabia Flora malsabidilla, a partir de su comparación con La gitanilla cervantina, en lo que respecta al género literario (el paso de novela a comedia en una obra híbrida, algo a lo que Salas Barbadillo era aficionado ${ }^{7}$ ); al personaje femenino (de bondadoso a falso) y al tema del matrimonio (que en la novela es un premio a la virtud de los enamorados, y en la comedia se plantea como venganza o castigo).

En cuanto al género literario, la barrera que separa los géneros de la ficción áurea es imprecisa, como demuestra la prohibición de la Junta de Reformación, donde novelas y comedias van a la par. La suspensión de licencias para publicar comedias y novelas entre 1625 y 1634 (Moll 1974) indica que ambos géneros se consideraban potencialmente dañinos para la moral, y explica la variada terminología que utilizan los autores para designar sus obras: basta recordar el caso de Lope y su Dorotea (1632), una acción en prosa (Moll 1979). En este sentido, Salas Barbadillo lleva a cabo una adaptación oportuna, como la que hicieron algunos autores extranjeros (Ruiz Álvarez 1995), quizá por considerar el origen gitano de Flora más apropiado y verosímil para el teatro que para una novela.

La sabia Flora malsabidilla ${ }^{8}$ consta de un Prólogo «Al vulgo», tres actos de distinta extensión y unos personajes relativamente tópicos (dama y galán, criados y amigos de los dos sexos), para un argumento con temática apicarada, adobado con algún lance burlesco de capa y espada, y en el que abundan poemas y canciones. El autor califica su obra de «alegoría», «fábula verosímil, no verdad historial» (Al vulgo), y solicita al lector que reciba la «doctrina que debajo della se contiene...» «con silencio», lo que se contradice con la presentación de su Flora... en tiempos de Carnestolendas. ¿Es obra de burlas, aprovechando la vena picaresca, tan en boga; o ejemplar, en recuerdo de la cervantina, recalcando deliberadamente los diminutivos «gitanilla»/«malsabidilla»?

A este respecto véase Cayuela 2013.

8 En adelante citamos por la ed. de Madrid, Luis Sánchez, 1621. 
A este último respecto destaquemos que Cervantes situó La gitanilla en el primer lugar de la colección, como una declaración de principios sobre la novedad de su obra (que las novelas eran suyas «no imitadas ni hurtadas», decía el Prólogo), porque hasta entonces apenas había entrado el tema de los gitanos en la narrativa9, y menos aún su protagonismo, aunque hubiera menciones aisladas como pinceladas de ambiente. Así que la etnia gitana de Flora, declarada en el primer acto, parece indicar que Salas Barbadillo sigue esa huella, para luego someter a la protagonista a modificaciones importantes. En efecto, si la primera de las novelas cervantinas, bajo su apariencia amable e idealizada, es una de las que mejor mezclan amor, matrimonio y bienes materiales, el desinterés de la gitana Preciosa es la característica más ínverosímil en una mujer de su condición (criada entre gitanos y viviendo como ellos), sólo explicable cuando llegamos a la anagnórisis. Este detalle merece subrayarse, frente a la omnipresencia del interés material en La sabia Flora, de Salas Barbadillo, cuya protagonista es una auténtica gitana, y muy rica.

En comparación con la novela de Cervantes, La sabia Flora malsabidilla destaca por la continua alusión a la «cultura material», como ha señalado García Santo Tomás (2008: 167-173), que se ha referido a nuestra obra estableciendo paralelismos con La gitanilla. Sin embargo, no hay mayor antítesis al desprendimiento y la virtud de Preciosa que la astucia sin escrúpulos de la gitana Flora — sabia, experimentada (a pesar de que sólo tiene diecisiete años) y muy rica一, que ha conseguido hacienda con su mala vida, y que logrará la respetabilidad al final de la obra, a través de un matrimonio con un indiano rico, que fue, además, su primer galán. Si había apariencias engañosas en la novelita cervantina - y recordemos el verbo «parecer» al comienzo: «Parece que los gitanos y gitanas nacieron... para ser ladrones; nacen de padres ladrones, críanse con ladrones, estudian para ladrones...» (73) - , la confusión de nombres e identidades en La sabia Flora... es continua, trastoca la anagnórisis, siembra las dudas sobre los orígenes de la protagonista, e impone en el desenlace un traslado a las Indias, donde marchaban los que tenían algo que ocultar.

Además de la ambigua anagnórisis — la dama recogida Flora se parece muchísimo a la gitanilla Gabiela-, pueden destacarse en la obra detalles notables sobre la cuestión genérica. En primer lugar el que Salas escriba una comedia en tres actos, pero en prosa, siendo un buen versificador, como demuestran las muchas composiciones que adornan la obra. $\mathrm{Y}$ en segundo lugar, que la gitana Flora narre su vida en primera persona en el primer acto (3-5), que es el más largo de los tres; y que esa autobiografía se complete con la información poco halagüeña que el hermano del enamorado Teodoro, Marcelo, nos ofrece de la gitana más adelante:

9 Lo señaló Avalle Arce en su edición de 1982, por la que citamos, remitiendo sólo a Gil Vicente y Lope de Rueda. 
...Parécese a la más baja pícara de todo el gitanismo, bien que bellísima. ¡Oh si supiésedes todos los buenos pasos de la mozuela trotona, su mucho embuste y sutilísimo embeleco! (61v).

¿Con aquella doña harapo, acechadora de faldriqueras, desaparecedora de trastos, hija de un padre que murió tan paciente que sufrió encima de sí otro hombre...?(62r).

En la línea de las autobiografías picarescas, Flora dice su primer nombre, «el sol de Egipto», y cómo cierto mozuelo que era hidalgo y que conoció con doce años, intentó seducirla y, al no lograrlo, destrozó deliberadamente su reputación. En lo sucesivo la gitana vive de los hombres y, con la perífrasis «entregué a un rico lo que le hizo pobre en dos años, pasando de sus manos a las mías» (4) indica su enriquecimiento, y cómo se convirtió en «pasto común» en la corte $(4 \mathrm{v})$, hasta llegar al presente de su relato. La presencia en Madrid de aquel joven, ahora indiano rico - el enamorado y cuasi poeta Teodoro - desencadena un cambio de identidad en la protagonista, su aparente recogimiento y cambio de nombre y de vida («puse en pregón mis joyas y galas»). Efectivamente mudó de barrio y de apellido (adoptó el del antiguo galán, de ahí el fingirse ahora su prima), cambió de criadas y de traje, y puso en seguro su fortuna: «compré juros, fundé censos...» (5); todo con el fin de engañar a Teodoro y lograr que se case con ella creyéndola dama virtuosa.

Al margen del movimiento dramático entre espacios sólo aludidos en la obra (Sevilla, Sanlúcar, las Indias), y de los cambios de escenario en el Madrid cortesano (las calles, las casas de los personajes, los espacios públicos habituales en la literatura costumbrista), todo en ella recuerda a una comedia-novelesca, parafraseando la terminología de Yudin (Yudin 1969), y confirmando las relaciones intergenéricas barrocas ${ }^{10}$.

Por otra parte, el mundo cervantino de La gitanilla y la selección femenina llevada a cabo por Salas coinciden con uno de los periodos de hostilidad contra los gitanos en las dos primeras décadas del siglo XVII, llegando al intento de expulsión en la villa de Madrid, según una disposición de 1611 (Tropé 2014). En efecto, el análisis realizado sobre las minorías gitanas muestra una oscilación entre persecuciones e intentos de integración, que refleja miradas diferentes sobre una «vil canalla» de imposible asimilación, pero también deseos de incorporarlos a la sociedad como elementos exóticos, festivos y burlescos.

Esos dos tipos de política aplicados por las autoridades suelen reflejarse en las obras literarias que recogen la presencia gitana, en España y también en el extranjero (Rodríguez de Lera 2000), como ya ocurrió con la de los moriscos. En el caso que nos ocupa, la mirada cervantina al inicio de La gitanilla coincide con la opinión general sobre su dedicación sistemática al robo y al engaño, que denunciaban

10 Para esta cuestión véase también Morínigo (1957) y Bonilla Cerezo, Trujillo y Rodríguez (2012). 
otros documentos de la época, y que incidían igualmente en sus libertades para emparejarse. Esto último es desmentido por la castidad de Preciosa que, sin embargo, sí cumple la función festiva de las gitanas que cantan y bailan en público. Lo inverosímil, como opinaba Sorel, a propósito de las que pedían limosna en París, es que fueran limpias, sinceras y virtuosas como Preciosa. En este sentido, Salas Barbadillo parece compartir la mirada más negativa y habitual sobre la etnia gitana, renunciando a presentaciones alegres, musicales y folklóricas. Por el contrario, se explaya sobre los engaños y disimulos de Flora, así como sus caprichos sexuales, que ella misma declara en un parlamento, sin que el autor tome partido como haría un narrador de novela. Así la gitana Flora se convierte en un personaje inquietante por su astucia y sabiduría, lo que entroncaría con el punto de vista mayoritario en contra de su raza.

Sin embargo, novela y comedia coinciden en pintar la presencia y función del dinero o de la riqueza, en general, sin duda por considerar los dos autores que era propio de los gitanos el robarlo o conseguirlo como fuera. En La gitanilla el dinero está presente desde el comienzo, porque Cervantes describe a la protagonista en el ambiente de los gitanos, a los que considera ladrones. Después, uno de los asistentes al baile callejero, el paje-poeta-pobre, regala a Preciosa un escudo envuelto en su soneto. Luego las gitanas llegan a casa del corregidor y piden moneda.Y por fin, pero todo al comienzo del relato, se nos presenta detenidamente a un «mancebo gallardo», el joven don Juan-Andrés Caballero, descrito con todo detalle en su rica vestimenta y adornos («con espada y daga que brillaban como un «ascua de oro»), que declara su amor por Preciosa y ofrece dinero a cambio, o en promesa, de matrimonio. Así, las joyas y los objetos de valor se repiten constantemente en la obra, pero dotados de simbología, como comprobamos al final de la novela, cuando el reconocimiento o anagnórisis de Preciosa-Constanza, se realiza, precisamente, gracias a unas joyas: unos brincos o dijes, indicio de la joya encontrada, como Preciosa lo es para sus propios padres. De tal modo que los orígenes familiares justifican, a posteriori, el comportamiento insólito y ejemplar de la falsa gitana, acorde con el desinterés crematístico de su prometido; así se augura un matrimonio feliz desde el punto de vista moral y también social, borrando la desigualdad entre ambos.

También en la obra de Salas Barbadillo se percibe esa presencia de los bienes materiales, por la fortuna de Flora y el oro de las Indias de Teodoro. Este enamorado coincide con Andrés en su enamoramiento, porque ambos están dispuestos a superar las desigualdades sociales, aunque sólo Andrés da el paso decisivo de declarar su amor, mientras que Teodoro se marcha a las Indias y lo reconoce a su vuelta: «...vive Dios que la moçuela era un serafín tan atractivo que, si no fuera por la vileza de su calidad, me casara con ella; tan apasionado y rendido me tuvo» (62r). En este sentido, Salas Barbadillo relaciona dos tipos literarios, la gitana y 
el indiano (tantas veces desprestigiado), frente a la noble ascendencia de Andrés y Constanza.

En cuanto al personaje, los títulos de las Ejemplares indican la importancia de los femeninos en la colección cervantina (gitanilla, española inglesa, ilustre fregona, dos doncellas, señora Cornelia), a lo que se añade la novedad de atribuir a la protagonista gitana la virtud de la castidad. Si Preciosa es un personaje insólito, su reflejo en La sabia Flora malsabidilla es una gitana más convencional: nada virtuosa.

A propósito de las características de las protagonistas, hay que insistir en el desinterés de la cervantina cuando se trata de un matrimonio por dinero, como el que propone Andrés Caballero, precisamente porque la gitanilla lo obtiene de varias maneras, aunque, en general, se gana la vida cantando y bailando por las calles con sus compañeras. Es verdad que no es una ocupación recomendable para una dama, pero sí para la gitana virtuosa. Por el contrario, la gitana de mala vida Flora finge recogimiento y apenas sale de un espacio doméstico perfectamente adaptado a sus apetencias - con un amante escondido y disfrazado de mujer- y a sus proyectos: un enamorado indiano que la visita y corteja continuamente.

Ya antes de la propuesta matrimonial de Andrés, Preciosa pide por decir la buenaventura en casa del teniente un escudo de oro, o un real de a ocho, o un real de a cuatro, aunque termina por conformarse con un cobro en especie: un dedal de plata. Todo ello da pie a la ironía de Cervantes en boca de la ingeniosa gitana, asombrándose de la pobreza y honradez del teniente, y recomendando que coheche como todos, aludiendo a la corrupción de los cargos públicos: «Coheche, vuesa merced $[\ldots]$, coheche y tendrá dineros, y no haga usos nuevos, que morirá de hambre» (95).

En ese contexto Preciosa rechaza la propuesta de matrimonio de Andrés, mediante un largo parlamento que replica al del caballero; y esto sorprende, puesto que el discurso de la gitana inteligente y virtuosa es poco creíble: empezando por la declaración de recato y siguiendo por la alabanza de su único valor, concepto que adquiere una dignidad moral superior a la monetaria: «...Una sola joya tengo, que la estimo en más que a la vida, que es la de mi entereza y virginidad, y no la tengo de vender a precio de promesas ni dádivas...» (99-100).

En este fragmento destaca la castidad de Preciosa, que se ha comparado con actitudes santas y virginales (Boyd, 2013), con las que Flora no comulga (admite una «doncellez fingida»), aunque sus reflexiones sean también lúcidas, y hasta muy críticas, por ejemplo con respecto a hidalguías fingidas:

...allá se atrevió a decir que era hidalgo, y se salió con probarlo, cosa que a los más sucede, porque juntándose a concejo los que son de una propia patria juran los unos por los otros y se despachan ellos mismos las executorias... (3r). 
Más inverosímil aún es que Preciosa se declare contra las leyes gitanas, porque las considera una «bárbara licencia» (12), y establece las suyas para aceptar un matrimonio futuro: que el galán ha de someterse a un periodo de prueba y familiarizarse con el ambiente gitano, que aprenderá en sus «escuelas», con una terminología metafórica muy usada en la época. Esto se opone a un comportamiento femenino movido por el interés material, denunciado en la literatura en múltiples ocasiones; por ejemplo en la Universidad de amor y escuelas del interés (1636), atribuida a Antolínez de Piedrabuena (Egido 1978), una pieza burlesca (Arredondo 2009) con mujeres dedicadas a engañar y sacar dinero a sus amantes.

Antes de la Flora malsabidilla, Salas Barbadillo ya bordeó la cuestión de la mujer interesada en muchas obras que tienen el aliciente para la historia literaria de ser obras mezcladas, y que demuestran que amor-dinero-matrimonio son cuestiones omnipresentes en esas misceláneas de novela y comedia, tan costumbristas, que cultivaron Salas Barbadillo y Castillo Solórzano. Por ejemplo, en el entremés Las aventureras en la corte, incluido en Fiestas de la boda de la incasable mal casada (1622), muy próximo a la fecha de nuestra Flora..., Salas habla de «tomajonas» (Arredondo 1993: 12), y recoge las palabras de un padre cortesano muy permisivo con las actividades de sus hijas: «Ésa es la industria, ésa es la fineza del ingenio, que, sin ser mujeres de mal vivir, ponen cerco a una bolsa, y asaltando las murallas de una faltriquera, la toman...».

En comparación con La gitanilla, Flora es el polo opuesto a la sinceridad y la virtud de Preciosa, porque Salas trata el matrimonio de esta astuta gitana como venganza de quien la infamó. Sin embargo, el personaje de Flora es bien complejo, porque sólo se dedica a la mala vida tras ser injuriada por el mozuelo despechado: «Corrido de no haber llevado vitoria de una mujer tan humilde, se alabó de que había gozado con las obras aquello de que ni aún el sí tuvo con las palabras» (4). Por ello «voló la voz desta infamia y caí en las manos del desprecio común». Entonces es cuando inicia la gitana su carrera de ramera, hasta llegar a Madrid para vengarse del que es ahora indiano rico: «haciéndole que se case conmigo después de tantas afrentas, para que con su propia honra se enmiende la deshonra que con sus engaños dio principio» (5r).

Esta Flora de ascendencia gitana es el eje del argumento, mediante la traza del falso recogimiento para lograr un matrimonio con el seductor que marcó su vida. En esta trama es importante la presencia de los bienes materiales y el dinero, porque los dos personajes lo poseen: ella lo disimula en aras de una aparente austeridad, y él lo exhibe para conseguir su favor. Lo más inquietante para el lector es el triunfo final de la apariencia y el fingimiento: un matrimonio lleno de dudas (ella declara su verdadero origen, que él no quiere creer) y logrado a base de dinero; y es que Camila, la amiga y alcahueta de Flora, recibe dádivas dobles por cooperar al matrimonio de conveniencia: de Flora obtiene una escandalosa cantidad — «mil 
escudos de oro que están en aquella escribanía» (161) - y del caballero enamorado Teodoro una valiosa joya de diamantes (149).

En cuanto al tema del matrimonio, es un desenlace casi obligado y esperado en las novelas cortas. En las Novelas Ejemplares y su descendencia aparece una variada casuística del amor: el deseo-pasión, los celos, y lo que puede considerarse una degeneración: el atropello sexual, como en las violaciones de La ilustre fregona y La fuerza de la sangre, que en La sabia Flora se reducen al cortejo y la murmuración o maledicencia posteriores. A través de múltiples ejemplos de la novela corta se percibe cómo la mujer estaba abocada al matrimonio; la diversidad de enfoques del mismo, desde el más convencional concertado por los padres a la promesa incumplida de matrimonio y la secuela tópica de la mujer disfrazada de varón (Bravo Villasante, 1976), muy bien reflejada en Las dos doncellas, con un travestismo que también recoge Salas en escenas más picantes, desbordando la confusión de géneros frecuente en las comedias de la época; hasta la cuestión de las dotes, y las relaciones entre amor-matrimonio-economía presentes en nuestras dos obras, novela y comedia.

Entre las muchas alusiones al tema dinero-matrimonio en La sabia Flora... destacan, por ejemplo, la mención al marido paciente o consentidor, tan propio de la picaresca, a propósito del de Camila; de él se dice que fue marido examinado (en alusión a otra obra del propio Salas Barbadillo, El sagaz Estacio, marido examinado (128v): «...que para precio de un buen marido ningún dinero es suficiente...» (129v). También demuestran la fuerza del dinero las palabras de Teodoro, ya picado de celos y deseoso de conseguir a Flora, frente a otro competidor:

...gastaré en un día si fuere necesario ciento y treinta mil pesos que truje de las Indias, compraré con la hacienda mi gusto, porque en no siendo ella medio de conseguille a él, la hacienda peso es y embaraço (115v).

En este sentido son especialmente interesantes las frases de Camila sobre las mujeres que deseaban matrimonio en la corte, mezclando boda y hacienda:

En lugar está donde hallará mujeres que le traigan calidad y hacienda, y otras que le quiten lo uno y lo otro. No hay padre que no ande sobrado de hijas, que ya como otras mercaderías andan en boca de los corredores, y entre cuantas mohatras ellos dan no es ésta en la que menos se pierde $(107 \mathrm{v})$.

El párrafo se cierra con la distinción entre «dama» $\mathrm{y}$ «mujer propia»: «para dama, como tenga buen parecer, ninguna es mala, para esotro fin pocas son buenas». Y todo se remata con la visión pesimista del caballero Marcelo sobre un tiempo oscuro, sin valores morales, lo que él llama «miseria de este siglo», en el que «están las cosas tan confusas que parece que no se ven con distinción» (108). 
Efectivamente, los dobles sentidos campan por toda la comedia y se consumarán en el desenlace, empezando por los equívocos sexuales del personaje doble Claudio-Claudia. Éste es un travestido que asume varias personalidades y que posteriormente se llamará Federico, fingiéndose pariente de Flora: «Claudio dize que está ya muy cansado de ser Claudia, porque estas nuestras faldas le sirven de grillos y tu continuo recogimiento de prisión estrecha» (92). El mismo también pide cobrar por sus servicios sexuales (escasos, en opinión de la gitana), discutiéndose sobre si ha de cobrar en plata o en cuartos: «...pide licencia para irse, y que le pagues por meses lo que ha trabajado en tu casa, pues ya sabes tú que ha hecho mucha labor y muy buena [...] la labor confieso que ha sido buena, pero no mucha...» (92).

A través de todo ello captamos un panorama burlesco y costumbrista del Madrid cortesano. Por ejemplo, Roselino se refiere a las mujeres de la corte como «salteadoras de nuestras bolsas» $(79 \mathrm{v})$, y menciona los barrios peligrosos para esas bolsas de los galanes: «la platería, la calle Mayor, la Puerta de Guadalajara» (79v), es decir, lo que en 1646 Baptista Remiro de Navarra llamó Los peligros de Madrid. En el acto tercero se acentúa el aspecto cómico por medio del criado Molina, especie de gracioso y personaje fundamental para el desenlace: primero narra una boda burlesca y la importancia de la dote, porque el marido quiso dotar a la segunda esposa con la dote de la primera (126); luego actúa como medianero de Teodoro, y está convencido de que, superando en hacienda a su competidor, «venceremos en la empresa» (127); después se presenta como el «oriplateado y el platidorado» (131), porque dormía entre las barras del precioso metal que traía desde Sevilla a Madrid; y finalmente dice que tenía «...el alma de papel librada en cuatro libranzas» (130v), poniendo a los pies de Flora «los ricos despojos que trae de las Indias» (133).

Precisamente la riqueza de las Indias condiciona el argumento, primero, por la fortuna del indiano enamorado; segundo, por las palabras del mismo Teodoro comparando una jornada de bodas con la jornada de Indias: «en ella (la de Indias) se gana y en aquella [las bodas] se gasta» (107v); por último, tras la boda, por su decisión de volver a las Indias, donde Flora pasará por mujer de calidad.

Esta visión satírica de Salas, desprovista de idealismo, es más propia de la comedia que de la novela idealizada a la manera de La gitanilla, pero coincide, en cambio, con el tono apicarado de El casamiento engañoso. En esta última destacaba la novedad cervantina de presentar al inicio de la trama el matrimonio como conflicto, por inconveniente y falso. Y en la misma línea es elocuente el flashback de Teodoro, quejándose del amor, que le fue hostil en el pasado — «no me espanto de que antes que pasase a las Indias, siendo pobre me despreciase aquella gitanilla humilde, en la sangre digo...» (144)—; y lamentando que ahora, cargado de riquezas («rico, armado de oro y diamantes»), pueda ser superado por 
un competidor que no le aventaja en nada (145). De ahí que, ante las palabras de Flora, que declara la verdad para no correr el riesgo de un matrimonio nulo - «mi nombre es Gabriela y mis padres unos gitanos humildes» (163)—, el enamorado Teodoro termine aceptando la falsa verdad y afirmando ante testigos: «...yo, don Teodoro, doy la mano de esposo a la señora Gabriela, constándome que es hija de padres gitanos y humildes» (164). Fruto de su recelo (porque ya no sabe si la gitana lo es, o lo finge) es la frase siguiente, donde el silencio hipócrita se impone sobre la autenticidad: «...no hay sino tener prudencia y silencio. Volvereme con ella a las Indias, donde pasará por mujer de la calidad que yo quisiere dalla...» (164r-v).

Así el final de la obra es el triunfo de una gitana nada virtuosa, suficientemente lista para vivir de hombres ricos y acumular una gran fortuna, vengadora de su fama mediante el matrimonio, y transformada en sabia y prudente. Desde el matrimonio idealizado de La gitanilla, o el más habitual matrimonio de conveniencia, llegamos al caso extremo de casarse por venganza. Por eso el tema del matrimonio en La sabia Flora... muestra una representación negativa del mundo propia de una cultura material y de los bajos instintos, y el autor lo propone como advertencia o doctrina — «la doctrina que debaxo della se contiene...» (Al vulgo) — frente al desenlace amable de Cervantes.

Sin insistir en cuestiones raciales, pero justificando la mala vida de Flora con los orígenes familiares, Salas se atiene al tratamiento habitual que reciben los gitanos en la literatura de la época; pero le añade un cierto desasosiego con el triunfo de la gitana - ahora prudente y sabia, que no malsabidilla - sobre el indiano rico, pintado sin simpatía alguna. Por los equívocos de las últimas páginas, tan ágiles como divertidos, ese triunfo es más propio del arte dramático que del narrativo, y refleja el acierto de Salas Barbadillo en el cambio genérico: la comedia en prosa, sin apartes ni apenas didascalias, recoge los equívocos y cambios de escenario habituales en una intriga cómica.

Así todo queda en el lugar que le corresponde, según los estereotipos de la época: el indiano Teodoro confuso, la dama-gitana Flora vengada de su deshonra de juventud, y el matrimonio resultante cubierto por el manto de respetabilidad material — que no moral- de los bienes de los contrayentes: los ahorros de la exramera y el oro de Teodoro procedente de las Indias, donde deciden volver para acallar murmuraciones cortesanas. En suma, de novelita corta a comedia en prosa.

Recibido: 16/09/2014

Aceptado: 15/10/2014 


\section{OBRAS CITADAS}

ArRedondo, María Soledad (1986). Charles Sorel y sus relaciones con la novela española. Madrid: Servicio de Reprografía de la Universidad Complutense.

(1987). «Las críticas a los libros de pastores: de la ironía a la parodia». Dicenda. Cuadernos de Filología Hispánica, 6, pp. 349-358.

(1993). «Pícaras. Mujeres de mal vivir en la narrativa del Siglo de Oro». Dicenda. Cuadernos de Filología Hispánica, 11, pp. 11-33.

(2006). «Castillo Solórzano y la mixtura barroca: poesía, narrativa y teatro en La niña de los embustes, Teresa de Manzanares». En El Siglo de Oro en escena. Homenaje a Marc Vitse. Toulouse: PUM, pp. 35-51.

(2009). «Carta a Claudio Guillén, con noticias sobre la Universidad de amor». En Francisco García Jurado, Margit Raders, Juan Felipe Villar Dégano (eds.), Claudio Guillén. Lecciones de un maestro, Madrid: Editorial Complutense, pp. 41-58.

(2012). «Prosa de ficción (novela y otros géneros en bibliotecas particulares 16511700». En José María Díez Borque (dir.), Álvaro Bustos (ed.), Literatura, bibliotecas y derechos de autor (1600-1700), Madrid: Iberoamericana-Vervuert, pp. 77-100.

- (en prensa). «Frontières et bibliothèques pour les Novelas du Siècle d'Or: Italie, France, Espagne».

Bonilla Cerezo, Rafael, José Ramón Trujillo y Begoña Rodríguez (2012) (eds.). Novela corta y teatro en el Barroco español (1613-1685). Studia in honorem Prof. Anthony Close. Madrid: Sial Ediciones.

Bourland, Caroline Brown (1927). The Short Story in Spain in the Seventeenth Century. Northampton: Smith College.

Boyd, Stephen (2013). «El misterio de la identidad personal en La gitanilla». Ínsula, 799800, pp. 11-14.

Bravo Villasante, Carmen (1976). La mujer vestida de hombre en el teatro español. Siglos XVI-XVII. Madrid: SGEL.

Cayuela, Anne (2013). «Coronas del Parnaso y platos de las musas de Alonso Jerónimo de Salas Barbadillo. Una miscelánea polisinodal bajo el reinado de Felipe IV». En María Soledad Arredondo (coord.), Géneros híbridos y libros mixtos en el Siglo de Oro. Mélanges de la Casa de Velázquez, 43, 2, pp. 69-94.

Cervantes, Miguel de (1982). La gitanilla. En Juan Bautista Avalle Arce (ed.), Novelas Ejemplares. Madrid: Castalia.

Cioranescu, Alexandre (1983). Le masque et le visage. Du Baroque espagnol au Classicisme français. Ginebra: Droz.

EGIDO, Aurora (1978). «La universidad de amor y La dama boba». Boletín de la Biblioteca Menéndez Pelayo, 54, pp. 351-371.

García SAnto-Tomás, Enrique (2008). Modernidad bajo sospecha. Salas Barbadillo y La cultura material del siglo XVII. Madrid: CSIC.

García Santo-Tomás, Enrique (2013) (ed.). Alonso Jerónimo de Salas Barbadillo, Don Diego de noche, Madrid: Cátedra.

GonzÁlez de Amezúa, Agustín (1956). Cervantes creador de la novela corta española. Madrid: CSIC. 
Goytisolo, Juan (1996). Disidencias. Madrid: Taurus.

Hautcoeur Pérez-Espejo, Guiomar (2005). Parentés franco-espagnoles au XVilème siècle. Poétique de la nouvelle de Cervantès à Challe. París: Honoré Champion.

Manoukian, Armine (2012). «Salas Barbadillo entre sus contemporáneos, sus gustos e influencias». En Carlos Mata Induráin y Adrián J. Sáez (ed.), Scripta manent. Actas del congreso internacional jóvenes investigadores siglo de oro (Jiso). Pamplona: Servicio de Publicaciones de la Universidad de Navarra, pp. 279-295.

Molt, Jaime (1974). «Diez años sin licencias para imprimir novelas y comedias en los reinos de Castilla: 1625-1634», BRAE 54, pp. 97-103. (1979). «Por qué escribió Lope La Dorotea». Anuario de la SELGYC, 2, pp. 7-11.

MorínIGO, Mariano A. (1957). «El teatro como sustituto de la novela en el Siglo de Oro», Revista de la Universidad de Buenos Aires, 2, pp. 41-61.

RIPOLl, Begoña (1991). La novela barroca, Catálogo biobibliográfico (1620-1700), Salamanca: Universidad.

Rodríguez Cuadros, Evangelina (1979). Novela corta marginada del siglo XVII español. Formulación y sociología en José Camerino y Andrés de Prado. Valencia: Universidad.

RODRÍGUEZ DE LERA, Juan Ramón (2000). «El tratamiento de los gitanos en la novela del siglo de oro y en las novels of roguery ». En José Enrique Martínez, María José Álvarez. María Luzdivina Cuesta, Cristina Garrigós, Juan Ramón Rodríguez (eds.), Estudios de literatura comparada. León: Universidad, pp. 215-231.

Ruiz Álvarez, Rafael (1991). «La transferencia de géneros, modelo de interpretación de otra cultura». En María Luisa Donaire y Francisco Lafarga (coords.), Traducción y adaptación cultural: España-Francia, Oviedo: Universidad, pp. 243-252.

(1995). «Rosset traductor e intermediario: de la novela de Cervantes al teatro de Hardy». En Francisco Lafarga y Roberto Dengler (coord.) Teatro y traducción. Barcelona: Universitat Pompeu Fabra, pp. 339-348.

Salas Barbadillo, Alonso Jerónimo de (1621). La sabia Flora malsabidilla, Madrid: Luis Sánchez.

Sorel, Charles (1627). Le Berger Extravagant París: Toussainct du Bray. (1966). La Bibliothèque Française. Myron Low Kocher (ed.). Chapel Hill: University of North Carolina.

TROPÉ, Hélène (2014). «Les gitans dans le royaume de Valence aux XVIe et XVIIe siècles». En Françoise Richet Rossi (ed.) Les minorités etniques et religieuses (XV-XXI siècles). La voie étroite de l'intégration. París: Michel Houdiard Editeur, pp. 119-153.

Yudin, Florence L. (1969). «Theory and Practise of the novela comediesca». Romanische Forschungen, 81, 4, pp. 585-584. 


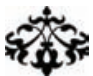

De La GitaNiLLA A La SABIA FLORA MALSABIDILLA. El GÉNERO, El PERSONAJE

Y EL MATRIMONIO

RESUMEN: Análisis comparativo de tres aspectos de La sabia Flora malsabidilla, que relacionan esta obra de Alonso Jerónimo de Salas Barbadillo con La gitanilla de Cervantes: el trasvase de la novela corta a la comedia, el personaje femenino de la gitana (de virtuoso a falso), y el tema del matrimonio por interés y por venganza.

Palabras Clave: Novela corta, Comedia en prosa, Personaje femenino, Matrimonio.

From La Gitanilla to La Sabia Flora malsabidilla. The Genre, the Character AND the MarRiage

ABSTRACT: This article is a comparative analysis about three aspects of La sabia Flora malsabidilla which links the work of Alonso Jerónimo de Salas Barbadillo to La gitanilla of Cervantes: the transfer to a comedy, the female character of a gypsi and the marriage by interest and revenge.

Keywords: Short novel, Comedy written in Prose, Female character, Marriage. 
Evangelina Rodríguez Cuadros (Universitat de València)

Novela cortesana, novela barroca, novela corta: de la incertidumbre al canon .9

Mita Valvassori (Universidad de Los Lagos)

El modelo narrativo del Decamerón en la Edad de Oro: una vieja historia .21

Antonio Gargano (Università degli Studi di Napoli Federico II)

«Difficile est proprie communia dicere»: el género de la novella entre

Boccaccio y Cervantes

Guillermo Carrascón (Università degli Studi di Torino)

Apuntes para un estudio de la presencia de Bandello en la

novela corta del siglo XVII

Leonardo Coppola (Università degli Studi «G. d'Annunzio» di Chieti-Pescara)

La proyección de Straparola en la novela española del Siglo de Oro desde una perspectiva editorial

Mireia Aldomì García

Didactismo, género literario y lector en Giraldi Cinzio.

María Jesús Zamora (Universidad Autónoma de Madrid)

«...En tiempo menos discreto que el de agora, aunque de hombres más sabios, se

Ilamaban a las novelas cuentos». La novela corta y el cuento en el Siglo de Oro.....109

Marcial Rubio (Università degli Studi «G. d'Annunzio» di Chieti-Pescara)

La contribución de Cervantes a la novela barroca: la ejemplaridad. .125

PIERRe Darnis (Université Bordeaux Montaigne)

La fuerza de la sangre, La ilustre fregona $y$ Las dos doncellas: ¿tres tipos

folclóricos?

María Soledad ArRedondo (Universidad Complutense de Madrid)

De La gitanilla $a$ La sabia Flora malsabidilla. El género, el personaje

y el matrimonio

Antonella Gallo (Università degli Studi di Verona)

Fabulaciones en equívocos burlescos: la Chrónica del monstro imaginado (1615)

de Alonso de Ledesma y novela corta barroca

David GonZález Ramírez (Universidad de Málaga)

El filósofo del aldea (1625) de Baltasar Mateo Velázquez: recepción textual

e hipótesis autorial.

Jonathan BRAdBury (University of Exeter)

La narrativa breve en la miscelánea del siglo XVII 
Cristina Castillo Martínez (Universidad de Jaén)

«La fuente del desengaño»: de las Noches de invierno de Eslava a la Tercera

Diana de Tejeda.

María Zerari (Université Paris-Sorbonne, CLEA)

Furor in fabula: La cruel aragonesa de Castillo Solórzano (o de la dama monstruo).. 241

Giulia Giorgi (Università degli Studi di Ferrara)

Alonso de Castillo Solórzano reescritor de sí mismo: algunas notas sobre los

Escarmientos de amor moralizados y el Lisardo enamorado .257

Angela Fabris (Alpen-Adria-Universität Klagenfurt)

El diálogo con el público y los espacios reales y de maravilla en

Casos prodigiosos y cueva encantada de Juan de Piña .267

María Rocío LePe García (IES San Sebastián, Huelva)

La traducción inglesa de Hipólito y Aminta: una adaptación

con fines comerciales 281

Andrea Bresadola (Università degli Studi di Udine)

La novela española en la Italia del siglo XVII: el caso de Il Feniso

de Francisco de Quintana

José Teruel (Universidad Autónoma de Madrid)

El triunfo del Desengaño. Marco y desengaño postrero de la Parte segunda

del Sarao y entretenimiento honesto, de María de Zayas

Nieves Romero-Díaz (Mount Holyoke College)

Lecturas alternativas en la Novela del fin bueno en mal principio

de doña Ana Francisca Abarca de Bolea.

Shifra Armon (University of Florida)

Compromiso y distanciamiento en La Venus de Ferrara

de Mariana de Carvajal Saavedra

Mechthild Albert (Rheinische Friedrich-Wilhelms-Universität Bonn)

Las "noches": un subgénero novelístico en perspectiva comparada.... .365

Fernando Copello Jouanchin (Université du Maine, Le Mans)

El mueble en la novela corta del Siglo de Oro: algunas reflexiones

en torno a la cama

Ilaria Resta (Università del Salento):

De la novella al entremés pasando por la novela corta: reescrituras del cuento

La gara delle tre mogli del Cieco di Ferrara. 


\section{EDAD DE ORO}

Revista de Filología Hispánica XXXIII

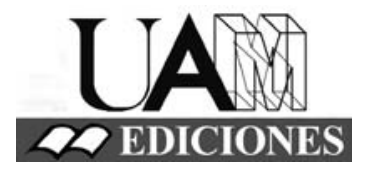




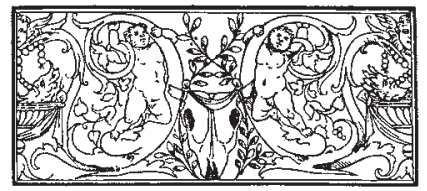

\section{Edad de Oro. Revista de Filología Hispánica}

ISSN: 0212-0429

Dirección:

Teodosio Fernández

Secretaría y edición:

José Ramón Trujillo

Coordinador del volumen XXXIII:

Rafael Bonilla Cerezo

Comité científico internacional:

Carlos Alvar (Univ. de Ginebra)

Ignacio Arellano (Univ. de Navarra)

Javier Blasco (Univ. de Valladolid)

Alberto Blecua (UAB)

Jean Canavaggio (Univ. de París X)

Laura Dolfi (Univ. de Turín)

Aurora Egido (Univ. de Zaragoza)

Víctor García de la Concha (RAE)

Luciano García Lorenzo (CSIC)

Joaquín González Cuenca (Univ. de Castilla-

La Mancha)

Agustín de La Granja (Univ. de Granada)

Begoña López Bueno (Univ. de Sevilla)

Michel Moner (Univ. de Toulouse III)

Joan Oleza (Univ. de Valencia)

Alfonso Rey (Univ. de Santiago)

Lina Rodríguez Cacho (Univ. de Salamanca)

Leonardo Romero Tobar (Univ. de Zaragoza)

Aldo Ruffinatto (Univ. de Turín)

Lía Schwartz (City University of New York)
Redacción y admisión de originales:

Teodosio Fernández

Edad de Oro

Departamento de Filología Española

Universidad Autónoma de Madrid

28049 Madrid (España)

Tfno.: +0034 914974090

correo: teodosio.fernandez@uam.es

Distribución, suscripción y venta:

Servicio de Publicaciones de la UAM

Universidad Autónoma de Madrid

28049 Madrid (España)

Intercambio de publicaciones:

Biblioteca de la Facultad de Filosofía y

Letras (UAM)

Universidad Autónoma de Madrid

28049 Madrid (España)

Han colaborado en este volumen:

Departamento de Filología Española (UAM)

Facultad de Filosofía y Letras (UAM)

Proyecto I+D FFI2013-41264-P La novela

corta del siglo XVII: estudio y edición (y II)

Edad de Oro se recoge en las siguientes bases de datos: SCOPUS, MLA Database, HLAS, Latindex, PIO-Periodical Content Index, ISOC, Dialnet, MIAR, ERIH, DICE, Sumaris CBUC, Ulrich's. Se encuentra evaluada en CIRC: A; INRECH: primer cuartil, posición 6 de 50; MIAR difusión ICDS live: 9.977; SCImago Journal \& Country Rank: H Index 2, SJR 0,101, Q4; RESH índice de impacto: 0.162; ERIH: A INT1; Carhus Plus+: B. 